\title{
АНТИБИОТИКОРЕЗИСТЕНТНОСТЬ ВОЗБУДИТЕЛЕЙ БАКТЕРИАЛЬНОЙ ИНФЕКЦИИ ПРИ ВНЕБОЛЬНИЧНОЙ ПНЕВМОНИИ, АССОЦИИРОВАННОЙ С COVID-19
}

\author{
Л. В. Катаева, Т. Ф. Степанова, К. Б. Степанова, О. В. Посоюзных, В. В. \\ Ташланова, Н. Ф. Карпухина, О. Н. Колотова, Ю. Н. Калашникова, А. А. \\ Вакарина
}

ФБУН «Тюменский научно-исследовательский институт краевой инфекционной патологии» Роспотребнадзора, г. Тюмень

Представлены результаты исследований антибиотикорезистентности штаммов, выделенных от пациентов с диагнозом внебольничная пневмония в период пандемии новой короновирусной инфекции, вызванной SARS-COV-2. Проведенный анализ чувствительности бактерий к антимикробным препаратам показал, что наибольшие уровни резистентности выявлены у штаммов Acinetobacter baumannii, Enterococcus faecium и Klebsiella pneumoniae. Статистически значимых различий по резистентности изолятов к АПМ в зависимости от наличия SARS-CoV-2 не отмечено. При этом фиксируются тенденции более высокого уровня резистентности штаммов Klebsiella pneumoniae, и в целом представителей семейства Enterobacteriaceae, Pseudomonas spp., Haemophilus spp. и Staphylococcus spp., изолированных от пациентов с неподтвержденным наличием SARS-CoV-2.

Ключевые слова: антибиотикорезистентность, внебольничная пневмония, COVID-19, штаммы бактерий.

Внебольничная пневмония (ВП) представляет собой серьезную медикосоциальную проблему здравоохранения России, так как является патологией, распространенной в разных возрастных группах населения [1]. В условиях пандемии новой короновирусной инфекции уровень заболеваемости ВП очень высокий, зачастую с осложненным и затяжным течением, обусловливающим значительные затраты на лечение и временную потерю трудоспособности.

Основой адекватного этиопатогенетического лечения бактериальных инфекций является рациональная антибиотикотерапия. Выбор антимикробной терапии основывается на выявлении возбудителя и определении его антибактериальной чувствительности. Также важной составляющей, которая оказывает влияние на выбор антибиотика, являются региональные или локальные особенности резистентности бактериальных агентов. В связи с этим чаще используют комбинации антибиотиков из различных групп препаратов, увеличивают дозу и длительность приема в рамках рекомендаций.

В настоящее время распространение антибиотикорезистентности приняло глобальный характер. Инфекции, вызванные резистентными штаммами, чаще требуют госпитализации и увеличивают продолжительность пребывания в стационаре, ухудшают прогноз для пациента, по сравнению с инфекциями, 
вызванными чувствительными микроорганизмами, результатом чего является более высокий показатель летальности $[7,9]$.

Рациональная антибактериальная терапия ВП невозможна без современных знаний этиологической структуры заболевания и антибиотикорезистентности возбудителя.

Цель исследования: установить частоту циркуляции резистентных клинических штаммов, изолированных из содержимого нижних дыхательных путей пациентов с диагнозом внебольничная пневмония, ассоциированной с SARS-CoV-2.

Материалы и методы. Материалом для исследования послужили 243 штамма бактерий, изолированных из содержимого нижних дыхательных путей пациентов, находящихся на стационарном лечении с подтвержденным диагнозом «внебольничная пневмония» различной степени тяжести. Сбор биоматериала (мокрота, промывные воды бронхов, бронхоальвеолярный лаваж), транспортирование и выделение культур осуществлялось в соответствии с нормативной документацией [4, 5].

Резистентность бактерий к антибиотикам определялась дискодиффузионным методом на среде Мюллер-Хинтон (HiMedia, Индия) в соответствии с действующими методическими указаниями [3, 6]. Чувствительность к антимикробным препаратам (АМП) Streptococcus spp. определялась к ампициллину, амоксициллин/клавулановой кислоте, клиндамицину, цефотаксиму. Бактерии рода Staphylococcus (20 штаммов) исследовались на чувствительность к ампициллину, амикацину, офлоксацину, ципрофлоксацину, левофлоксацину, имипенему, меропенему, цефокситину, клиндамицину, азитромицину. У штаммов бактерии рода Enterococcus (13 шт.) определялась чувствительность к ампициллину, амоксициллин/сульбактаму, амоксициллин/клавулановой кислоте, имипенему, меропенему, ципрофлоксацину, левофлоксацину, гентамицину, ванкомицину, цефепиму. Изоляты неферментирующих грамотрицательных бактерий (НГОБ - 39 шт.) и бактерий семейства Enterobacteriaceae (68) - к амоксициллин/клавулановой кислоте, амикацину, ципрофлоксацину, цефотаксиму, цефепиму, цефтазидиму, меропенему, имипенему, цефоперазон/сульбактаму.

\section{$\begin{array}{llll}\text { Результаты и } & \text { обсуждение. }\end{array}$} антибиотикорезистентности клинических штаммов, изолированных из содержимого нижних дыхательных путей пациентов, с подтвержденным диагнозом «внебольничная пневмония» представлены на рисунке 1. Наибольшие уровни резистентности выявлены у штаммов Acinetobacter spp., Enterococcus spp., Klebsiella pneumoniae. Важно подчеркнуть, что статистически значимых различий по резистентности изолятов к АПМ в зависимости от наличия SARS-CoV-2 не отмечено. При этом фиксируются тенденции более высокого уровня резистентности штаммов Klebsiella pneumoniae, и в целом представителей семейства Enterobacteriaceae, Pseudomonas spp., Haemophilus spp. и Staphylococcus spp., изолированных от пациентов с неподтвержденным наличием SARS-CoV-2. 


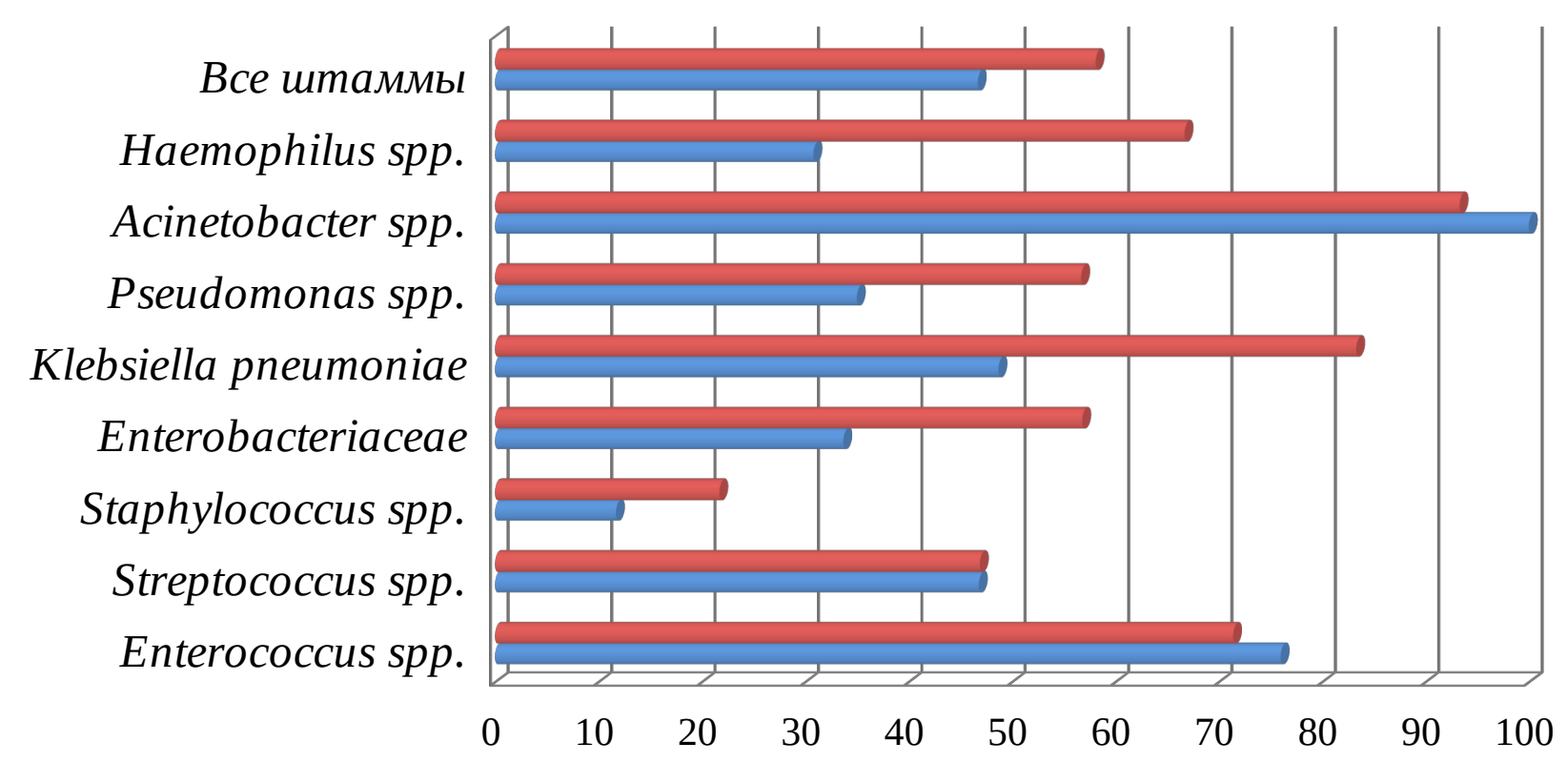

口ARS-CoV-2(не обнаружен) घ SARS-CoV-2 (обнаружен)

Рисунок 1. Резистентность к антимикробным препаратам бактерий, изолированных из содержимого нижних дыхательных путей больных с диагнозом внебольничная пневмония (\%)

Резистентность грамположительных клинических штаммов родов Streptococcus, Staphylococcus, Enterococcus, изолированных из содержимого нижних дыхательных путей, представлена в таблице 1. В группе штаммов Streptococcus spp. протестированы виды: S. mitis, S. parasanguinis, S. vestibularis, S. salivarius, S. oralis. Все указанные виды признаны доминирующей флорой слизистых верхних дыхательных путей, обеспечивающей нормобиоценоз у здоровых людей. Учитывая высокий уровень резистентности исследованных штаммов, представленный в таблице 1 , возможно предположить, что при возникновении хронического патологического процесса на слизистых верхних дыхательных путей происходят качественные и количественные изменения стрептококковой флоры, вследствие чего она утрачивает свои первоначальные функции. Штаммы S. pneuтопіае были изолированы от трех пациентов с подтвержденным COVID-19 и отличались резистентностью к азитромицину и клиндамицину. Среди бактерий рода Staphylococcus идентифицировались $S$. aureus и S. haemolyticus, от одного пациента выделен штамм S. warneri, резистентный к карбапенемам, азитромицину и цефазолину. Наибольшие уровни резистентности выявлены у штаммов S. haemolyticus. Штаммы бактерий рода Enterococcus, выделенные от пациентов, были представлены преимущественно видом E. faecium, проявляющим чувствительность только к ванкомицину.

Среди представителей семейства Enterobacteriaceae, кроме штаммов $K$. pneumoniae, были выделены: Serratia marcescens (абсолютно чувствительные штаммы), Enterobacter spp. (резистентность 3,8 \%), Pantoea agglomerans (8,3 
\%), Raoultella spp. (резистентность 22,2 \%), E. coli (резистентность их составила 25,0 \%), Morganella morganii (резистентность 28,6 \%), Proteus mirabilis (резистентность 44,7 \%). В целом, резистентность к АМП бактерий семейства Enterobacteriaceae и других грамотрицательных, чаще идентифицируемых изолятов, представлена в таблице 2.

Таблица 1. Антибиотикорезистентность грамположительных изолятов, выделенных от пациентов с диагнозом внебольничная пневмония, \%

\begin{tabular}{|l|c|c|c|c|c|c|}
\hline \multirow{2}{*}{ Антибиотики } & \multicolumn{2}{c|}{$\begin{array}{c}\text { Streptococcus } \\
\text { spp. }\end{array}$} & \multicolumn{2}{c|}{$\begin{array}{c}\text { Staphylococcus } \\
\text { spp. }\end{array}$} & \multicolumn{2}{c|}{$\begin{array}{c}\text { Enterococcus } \\
\text { spp. }\end{array}$} \\
\cline { 2 - 7 } & $\begin{array}{c}\text { Covid } \\
(+)\end{array}$ & $\begin{array}{c}\text { Covid } \\
(-)\end{array}$ & $\begin{array}{c}\text { Covid } \\
(+)\end{array}$ & $\begin{array}{c}\text { Covid } \\
(-)\end{array}$ & $\begin{array}{c}\text { Covid } \\
(+)\end{array}$ & $\begin{array}{c}\text { Covid } \\
(-)\end{array}$ \\
\hline Ампициллин & 75,4 & 70,9 & & & 88,9 & 100,0 \\
\hline $\begin{array}{l}\text { Ампициллин } \\
\text { /сульбактам }\end{array}$ & & & 66,7 & 57,1 & & \\
\hline $\begin{array}{l}\text { Амоксициллин } \\
\text { /клавулановая кислота }\end{array}$ & 68,8 & 73,3 & 66,7 & 57,1 & 87,5 & 100,0 \\
\hline $\begin{array}{l}\text { Амоксициллин/ } \\
\text { сульбактам }\end{array}$ & & & & & 100,0 & 100,0 \\
\hline Офлоксацин & & & 0 & 25,0 & & \\
\hline Ципрофлоксацин & & & 14,3 & 25,0 & 75,0 & 100,0 \\
\hline Левофлоксацин & & & 0 & 25,0 & 71,4 & 100,0 \\
\hline Имипенем & & & 45,4 & 40,0 & 100,0 & 100,0 \\
\hline Меропенем & & & 45,4 & 40,0 & 100,0 & 100,0 \\
\hline Цефазолин & 39,3 & 27,6 & 40,0 & 54,5 & 100,0 & 100,0 \\
\hline Цефотаксим & 11,4 & 3,0 & 36,4 & 50,0 & & \\
\hline Клиндамицин & & & 45,4 & 58,3 & & \\
\hline Азитромицин & & & 9,1 & 8,3 & & \\
\hline Амикацин & & & & & 66,7 & 100,0 \\
\hline Гентамицин & & & & & 0 & 0 \\
\hline Ванкомицин & & & & & \\
\hline
\end{tabular}

Высокий уровень резистентности к ампициллину и амоксициллин/ клавулановой кислоте в группе штаммов семейства Enterobacteriaceae регистрируется за счет бактерий E. coli и $P$. mirabilis. Продукция $ß$ - лактамаз также регистрируется у этих штаммов и не зависит от наличия SARS-CoV-2.

Спектр антибиотикорезистентности $K$. pneumoniae указывает на его высокий уровень, причем у штаммов, изолированных от пациентов с внебольничной пневмонией бактериальной этиологии (SARS-CoV-2 отсутствует). Этот факт подтверждается выявлением $ß-$ лактамаз у половины изолированных штаммов K. pneuтопіае.

Резистентность ко всем тестируемым АМП выявлена у штаммов Acinetobacter baumannii. Учитывая панрезистентность и значительную долю в 
структуре микробиоты содержимого нижних дыхательных путей при внебольничных пневмониях независимо от наличия у пациентов SARS-CoV-2, позволяет A. baumannii рассматривать в качестве этиологического агента бактериальной пневмонии.

Таблица 2. Антибиотикорезистентность грамотрицательных изолятов, выделенных от пациентов с диагнозом внебольничная пневмония, \%.

\begin{tabular}{|c|c|c|c|c|c|c|c|c|}
\hline \multirow{2}{*}{ Антибиотики } & \multicolumn{2}{|c|}{$\begin{array}{c}\text { Семейство } \\
\text { Enterobacteriaceae }\end{array}$} & \multicolumn{2}{|c|}{$\begin{array}{c}\text { Klebsiella } \\
\text { pneumoniae }\end{array}$} & \multicolumn{2}{|c|}{$\begin{array}{l}\text { Pseudomonas } \\
\text { spp. }\end{array}$} & \multicolumn{2}{|c|}{$\begin{array}{l}\text { Haemophilus } \\
\text { spp. }\end{array}$} \\
\hline & 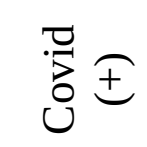 & 总 & 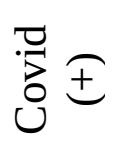 & 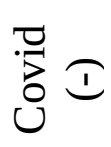 & 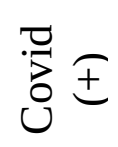 & 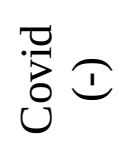 & 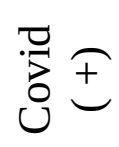 & 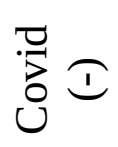 \\
\hline Ампициллин & 57,1 & 71,4 & & & & & & \\
\hline $\begin{array}{l}\text { Амоксициллин/ } \\
\text { клавулановая } \\
\text { кислота }\end{array}$ & 28,6 & 85,7 & 66,7 & 95,2 & & & 16,7 & 0 \\
\hline Амикацин & 12,5 & 10,0 & 33,3 & 60,0 & 28,6 & 62,5 & & \\
\hline Офлоксацин & & & & & & & 40,0 & 100 \\
\hline Ципрофлоксацин & 6,25 & 20,0 & & & 28,6 & 62,5 & 50,0 & 100 \\
\hline Имипенем & 6,25 & 5,0 & 30,8 & 72,0 & 28,6 & 62,5 & & \\
\hline Меропенем & 6,25 & 5,0 & 30,8 & 72,0 & 42,8 & 62,5 & & \\
\hline Цефепим & 12,5 & 17,6 & & & 33,3 & 75,0 & & \\
\hline Цефтриаксон & & & 61,5 & 87,5 & & & & \\
\hline Цефотаксим & 37,5 & 50,0 & 15,4 & 88,0 & & & & \\
\hline Цефтазидим & & & & & 40,0 & 75,0 & & \\
\hline $\begin{array}{l}\text { Цефоперазон/ } \\
\text { сульбактам }\end{array}$ & 0 & 0 & 33,3 & 80,0 & 16,7 & 100,0 & & \\
\hline Ко-тримоксазол & & & & & & & 50,0 & 50,0 \\
\hline БЛРС & 33,3 & 75,0 & 40,0 & 50,0 & & & & \\
\hline
\end{tabular}

В группе бактерий рода Pseudomonas превалировали штаммы $P$. aeruginosa, обладающие высоким уровнем резистентности к исследуемым АМП. Кроме того были изолированы штаммы P. oleovorans, P. fluorescens, $P$. putida. Штаммы $P$. oleovorans демонстрировали панрезистентность, $P$. fluorescens были резистентными только к цефалоспоринам III, IV поколения, указанным в таблице 2. Среди бактерий рода Haemophilus в основном обнаруживались $H$. parainfluenzae и чаще у пациентов при пневмонии, ассоциированной с SARS-CoV-2.

Таким образом, проведенный анализ циркуляции резистентных к АМП клинических штаммов, изолированных из содержимого нижних дыхательных путей пациентов с диагнозом внебольничная пневмония, ассоциированной с SARS-CoV-2 показал, что наибольшие уровни резистентности выявлены у штаммов Acinetobacter baumannii, Enterococcus faecium и Klebsiella pneumoniae. 
Статистически значимых различий по резистентности изолятов к АПМ в зависимости от наличия SARS-CoV-2 не отмечено. При этом фиксируются тенденции более высокого уровня резистентности штаммов Klebsiella pneumoniae, и в целом представителей семейства Enterobacteriaceae, Pseudomonas spp., Haemophilus spp. и Staphylococcus spp., изолированных от пациентов с неподтвержденным наличием SARS-CoV-2.

\section{Литература}

1. Карапетян, Т. А. Этиология внебольничной пневмонии в Карелии / Т. А. Карапетян, Н. В. Доршакова, Н. А. Ларина // Врач. - 2008. - № 2.- С. 39 - 41.

2. Катаева Л. В., Степанова Т. Ф., Степанова К. Б., Бакштановская И. В., Посоюзных О. В., Ташланова В. В., Карпухина Н. Ф., Колотова О. Н., Калашникова Ю. Н., Вакарина А. А. 2020. Микробиоценоз нижних дыхательных путей при пневмонии, ассоциированной с SARS-CoV-2. Covid19preprints.microbe.ru. https://doi.org/10.21055/preprints-3111755/

3. Клинические рекомендации «Определение чувствительности микроорганизмов к антимикробным препаратам» (утв. на расширенном совещании Межрегиональной ассоциации по клинической микробиологии и антимикробной химиотерапии (Москва, 15.05.2017). Версия-2018-03. 206 с.

4. МР 4.2.0114-16. Методические рекомендации. Лабораторная диагностика внебольничной пневмонии пневмококковой этиологии. - 2016. - 57 с.

5. МУК 4.2.3115-13. Методические указания. Лабораторная диагностика внебольничных пневмоний. - 2014.-39 с.

6. Определение чувствительности микроорганизмов к антибактериальным препаратам: МУК 4.2.1890-04. М.: Федеральный центр госсанэпиднадзора Минздрава России, 2004. 91 с.

7. Савенкова, М. С. Макролиды: современные исследования и показания к назначению «нового» кларитромицина / М. С. Савенкова // Детские инфекции. - 2012. - № 1. - С. 37 - 43.

8. Холодок, Г. Н. Лекарственная резистентность клинических изолятов возбудителей пневмонии у детей Приамурья // Г. Н. Холодок // Здоровье. Медицинская экология. Наука. - 2009. - № 2 (37). - С. 38-40.

9. Цыганко, Д. В. Исследование микробиологических особенностей инфекций нижних дыхательных путей в стационаре / Д. В. Цыганко, Н. Г. Бердникова // Национальная ассоциация ученых. Медицинские науки. - 2015. VI (11). - C. 36 - 39. 